\title{
Double uterus-hemivagina-renal agenesis syndrome
}

INSERM

\section{Source}

INSERM. (1999). Orphanet: an online rare disease and orphan drug data base. Double uterus-hemivagina-renal agenesis syndrome. ORPHA:3411

Double uterus, hemivagina and renal agenesis is a rare cong enital urogenital anomaly characterized by the presence of double uterus (didelphys, bicornuate or septumcomplete or partial), unilateral cervico-vaginal obstruction (obstructed hemivaginacommunicant, not communicant or septate and unilateral cervical atresia) and ipsilateral renal anomalies (renal agenesis (see this term) and/or other urinary tract anomalies). Patients are usually diagnosed at puberty after menarche due to recurrent severe dysmenorrhea, chronic pelvic pain, excessive foul smelling mucopurulent discharge, spotting and intermenstrual bleeding (depending on the existence of uterine or vaginal communications). Fever, dyspareunia, and a palpable abdominal, pelvic or vaginal mass (mucocolpos or pyocolpos) may also be present. 